\title{
ENSINO DE PORTUGUÊS DO BRASIL PARA HISPÂNICOS: A INTERLÍNGUA COMO POSSIBILIDADE DE INTERAÇÃO ${ }^{1}$
}

\section{TEACHING PORTUGUESE FROM BRAZIL TO HISPANICS: INTERLANGUAGE AS A POSSIBILITY FOR INTERACTION}

\author{
Flavio Biasutti Valadares ${ }^{2}$ \\ Jorge Rodrigues de Souza Junior ${ }^{3}$
}

\begin{abstract}
RESUMO: O artigo relata a experiência de ensino de Português do Brasil para Hispânicos. Objetiva mostrar como se processam em sala de aula as possibilidades de adequações sociocomunicativas a partir do uso da interlíngua, com base na metodologia de tarefas sobre trocas Espanhol-Português acionadas na interação. Propõe-se, também, o Português do Brasil como Língua Adicional, inserindo-a como uma forma acionar possibilidades de distinguir semelhanças e diferenças, disso decorrendo o desenvolvimento de habilidades sociolinguísticas. Utiliza a Linguística Aplicada ao Ensino como referencial teórico-conceitual, com base em pesquisadores como Celada (2000), González (1994), Kulikowski e González (1999), Kumaravadivelu (1994), Leffa (2012), Schoffen (2009) e Schön (2000). Conclui que o uso da interlíngua em turmas de Português do Brasil para Hispânicos, por meio de tarefas, é um facilitador de aprendizagem e de desenvolvimento de competências nos diversos contatos com brasileiros.
\end{abstract}

PALAVRAS-CHAVE: Interlíngua. Português do Brasil para Hispânicos. Língua Adicional. Ensino de Segunda Língua.

\begin{abstract}
The article assesses experiences of teaching Brazilian Portuguese to Hispanics. It aims to show how the possibilities of socio-communicative adjustments using an interlanguage perspective in the classroom, based on tasks requiring students to exchange Spanish and Portuguese vocabularies in their interaction. It is also proposed to develop Brazilian Portuguese as an Additional Language. It uses the theoretical and conceptual references of Celada (2000), González (1994), Kulikowski e González (1999), Kumaravadivelu (1994), Leffa (2012), Schoffen (2009) and Schön (2000). It concludes that the use of interlanguage in Brazilian Portuguese classes for Hispanics is a very facilitating means of learning and developing sociolinguistic and interactional skills.
\end{abstract}

KEYWORDS: Interlanguage. Brazilian Portuguese for Hispanics. Additional Language. Second Language Teaching.

\section{Introdução}

Inicialmente, destacamos, como indiciam Rottava e Silva (2013, p. 275), que muitos pesquisadores que investigam a influência interlinguística atribuíram "a interferência da primeira língua (L1) no processo de aquisição de língua estrangeira ou segunda língua (LE-L2), focalizando, em sua maioria, aspectos relacionados à ortografia, à fonologia e à morfossintaxe". Ao optarmos, em sala de aula, pelo trabalho com tarefas, precisamos nos atentar para as

\footnotetext{
${ }^{1}$ Artigo elaborado a partir da oferta do curso de extensão Português do Brasil para Hispânicos, Campus São Paulo, por meio da Coordenação de Extensão/Diretoria de Pesquisa, Extensão e Pós-Graduação.

${ }^{2}$ Pós-Doutorado em Letras/UPM-SP, Doutorado em Língua Portuguesa/PUC-SP. Docente do Instituto Federal de Educação, Ciência e Tecnologia de São Paulo, Campus São Paulo, SP, Brasil. Departamento de Humanidades DHU; ORCID: https://orcid.org/0000-0001-5399-6612. E-mail: flaviovaladares2@gmail.com

3 Doutorado em Letras (Língua Espanhola e Literatura Espanhola e Hispano-Americana)/USP. Docente do Instituto Federal de Educação, Ciência e Tecnologia de São Paulo, Campus São Paulo, SP, Brasil. Departamento de Humanidades - DHU; ORCID: https://orcid.org/0000-0002-5672-293X. E-mail: jorgersjunior@yahoo.com.br
} 
proximidades possíveis, em seus mais variados aspectos, para não nos limitarmos a aspectos estritamente de ordem gramatical.

Com isso, é necessário adotar alguns procedimentos para a consecução das propostas de ensino, de forma a garantir que o processo caminhe para uma efetiva aprendizagem, ou seja, pensar o ensino de Português do Brasil para Hispânicos também é fundamentalmente pensar como se pode proceder para que a interlíngua se configure como um mecanismo que auxilia o aprendizado sem, dessa forma, fossilizar usos e, simultaneamente, proporcionar uma inserção na cultura sociolinguística brasileira de modo que se obtenha êxito no processo de aprendizagem deste perfil de aprendente ${ }^{4}$.

Posto isso, nosso artigo objetiva relatar o percurso metodológico considerando a interlíngua como um fator de apoio eficaz em interações no contexto da sala de aula com aprendentes de origem hispânica, dadas as possibilidades que a aproximação entre as línguas traz como um ponto que, se utilizado de maneira equivocada, pode tornar o aluno um falante de "Portunhol", mas que, com uma orientação metodológica adequada, adquire contornos de aprendizagem legítima em termos, sobretudo, de pronúncia.

Neste artigo, preferimos a perspectiva de Língua Adicional, já que retratamos uma realidade específica, a saber: trata-se de um curso de extensão ofertado pelo IFSP/Campus São Paulo cuja proposta é a de atender à comunidade do entorno com necessidades que se ligam à exiguidade de oportunidades no mercado de trabalho por carência de habilidades sociolinguísticas; em específico a oferta de Português do Brasil para Hispânicos de origem boliviana, com ênfase no desenvolvimento da oralidade.

Consideramos, portanto, a designação Língua Adicional (LA) em detrimento da nomenclatura Língua Estrangeira (LE) por compreendermos ser mais adequada aos nossos objetivos, uma vez que valoriza o contexto social do aluno e possibilita uma visão crítica da língua no processo de aprendizagem, como atestam Schlatter e Garcez (2009). De acordo com esses autores, a aula na perspectiva de Língua Adicional

deve criar condições para que o educando possa engajar-se em atividades que demandam o uso dessa língua para refletir sobre temas relevantes ao seu contexto e ampliar sua atuação através da compreensão da sociedade em que vive, da circulação segura por diferentes gêneros do discurso e da possibilidade de expressar o que quer dizer. (SCHLATTER; GARCEZ, 2009, p. 134)

Além disso, identificamos que Língua Adicional ampara uma noção de língua como recurso para interações em práticas sociocomunicativas, configurando sua utilização como meio de integração tanto no cotidiano particular quanto no convívio social. Também, esclarecemos que não optamos pelas nomenclaturas Língua Estrangeira, L2 ou Português como segunda língua por se tratar de um contexto específico no qual os aprendentes são residentes em São Paulo e mantêm convívio com brasileiros em seu dia a dia. implica

Também, cabe menção à ideia de proficiência que, segundo Schoffen $(2009$, p. 115),

\footnotetext{
${ }^{4}$ Adotamos, pois, o termo aprendente (apprenenf) que, de acordo com Pereira (2003, p. 105), "foi criado por analogia com o termo estudante (étudiant) e surgiu nos anos noventa no seio da pedagogia canadiana [...]". Desse termo, apreendemos para aplicação em nossa prática as noções de que o aprendente possui um papel determinante nos processos de formação, conformando a ideia de que ele é alguém com uma experiência prévia, com reflexões e interrogações provenientes de seu desejo de aprender. Também, o estabelecimento de uma relação com aprendizagens a partir de identidades que o sujeito assume no processo, isto é, experiência e subjetividade configuram um caminho permanente e multiforme de aprendizagem (MOLINA, 2001; VOISIN, 2001; PEREIRA, 2003).
} 
Volume 15 - Número 1 - jan/jul de 2020

entender que os recursos linguísticos estão "a serviço" da interlocução, isto é, articulando as relações contextuais e interlocutivas à materialidade linguística para a produção de um texto de um determinado gênero. Proficiência é, dessa perspectiva, mais do que uma soma de regras de gramática e vocabulário ou um inventário de signos. Proficiência é a capacidade de agir na língua, e um falante é mais ou menos proficiente na medida em que suas ações são mais ou menos adequadas aos contextos de produção em que atua. (SCHOFFEN, 2009, p. 115)

Quanto às tarefas selecionadas para nosso relato, relatamos atividades orais com temas desenvolvidos sobre a vivência dos alunos no trabalho, na família e em suas rotinas cotidianas; temas diretamente relacionados à subjetividade (sentimentos, gostos, opiniões); usos de preposição observada sua inserção semântico-pragmática; e um roteiro no qual desenvolveram uma apresentação oral com informações de quando ainda se encontravam em seu país de origem, dados pessoais e profissionais (nome completo, idade, de que cidade e país é, profissão e do que mais gosta no Brasil), bem como a rotina da semana em São Paulo (o que faz, para onde vai, onde almoça etc).

Assim, compreendemos, nessas proposições, que os bolivianos precisam desenvolver suas habilidades para uso do Português do Brasil, a fim de que obtenham melhores possibilidades de uma inserção no mercado de trabalho paulistano/região metropolitana, visto que essa inserção demanda interações com brasileiros, além do que circulam em meio a grupos sociais e, naturalmente, poderiam integrá-los com êxito; ademais, muitos deles já constituíram família no Brasil e têm seus filhos, nascidos no Brasil, frequentando escolas brasileiras, muitas vezes, criando barreiras sociocomunicativas e linguísticas entre si.

Nessas perspectivas, relatamos nossa experiência com esse público aprendente. Para tanto, justificamos que os relatos de práticas docentes, segundo Delmanto e Faustinoni (2009, p. 9), "são registros de atividades realizadas com os alunos, com o objetivo de construir conhecimentos". Acrescentam as autoras: "são produções bastante significativas na medida em que permitem que a voz do professor seja ouvida, seja levada a outros tantos que têm as mesmas inquietações, a mesma vontade de criar e dar respostas a velhos desafios". Elas sinalizam que "os relatos possibilitam pôr fim à sensação de isolamento e impotência, permitindo que o conhecimento produzido seja socializado e colocado à disposição daqueles que dele podem se beneficiar". E ratificam a ideia de que, por meio deles, "é possível expor práticas, trocar experiências, explicitar planos futuros e analisar problemáticas comuns".

Nesse viés, compreendemos que os dados se constituem a partir da ênfase à importância da prática dos professores e das produções dos alunos, da vivência, por meio dos registros, das ações propostas e realizadas pelos aprendentes, da observação, análise e discussão dos resultados alcançados a cada momento e de sua consequente reflexão. Isso, aliado ao referencial teórico adotado da Linguística Aplicada ao Ensino, traduz a cientificidade requerida para a produção deste relato de experiência sob o formato do gênero textual acadêmico artigo científico.

\section{Aspectos teórico-conceituais}

Recorremos a Schön (2000) para localizar nosso relato, do ponto de vista pedagógico, uma vez que se baseia na ideia de que nossa prática docente precisa estar em termos de "reflexão-na-ação" e de "sua imediata significação para ação", com vistas à busca de um estímulo profissional que busque a interação teoria-prática em um percurso cujo processo "reflexão-na-ação" esteja voltado para o aprender a aprender e a refletir constantemente sobre sua ação. 
Como ponto de partida, via Linguística Aplicada, amparamo-nos em Kumaravadivelu ${ }^{5}$ (1994), citado, transposto e ampliado por Leffa (2012, p. 399-400), que trata de macroestratégias em relação ao ensino de línguas. São elas:

(1) maximizar as oportunidades de aprendizagem, tratando a sala de aula como uma prática social conjunta entre professor e alunos; (2) facilitar ao aluno interação negociada com o professor e com os colegas para acelerar a compreensão e construção de sentido, usando, por exemplo, atividades em grupo; (3) minimizar os desencontros perceptuais entre as intenções do professor e as interpretações do aluno; (4) ativar a heurística intuitiva dos alunos, fornecendo input linguístico suficiente para que eles possam chegar às regras da língua pela autodescoberta; (5) incentivar a consciência linguística do aluno, não com base nas regras tradicionais da gramática, mas por meio de atividades que evidenciem também a importância da língua em seus aspectos formais; (6) contextualizar o input linguístico, usando tarefas de solução de problemas, simulações, RPG, e outras atividades que integram vários componentes linguísticos; (7) integrar as habilidades linguísticas, incluindo a escuta, a fala, a leitura e a escrita; (8) promover a autonomia do aluno, dandolhe o conhecimento necessário para gerenciar sua própria aprendizagem; (9) aumentar a consciência cultural dos alunos, propiciando contato com diferentes culturas, incluindo a cultura da língua materna; (10) assegurar relevância social, partindo do contexto do aluno. (KUMARAVADIVELU, 1994, citado por LEFFA, 2012, p. 399-400)

Em nossa proposta, empreendemos algumas dessas macroestratégias, sendo que a percepção de sala de aula como lugar da prática social, a interação aluno-professor-colegas, a integração de habilidades linguísticas, a promoção da autonomia do aluno e o destaque para a relevância social - considerado o contexto do aprendente - são as que mais efetivamente se concretizaram ao longo das aulas. Nesse aspecto, vale ainda ressaltarmos que a metodologia por tarefas reforça o percurso metodológico na interface Português-Espanhol.

Por esse ângulo, afirmamos que, em diversos estudos linguísticos que comparam o Português e o Espanhol, sejam eles de um ponto de vista comparado a partir de alguns aspectos formais (como a determinação, a topicalização do pronome sujeito, o uso de clíticos pronominais e outras formas de pronominalização), sejam eles alicerçados a uma feição pósenunciativa, há a consideração da especial relação que se estabelece entre essas duas línguas em nosso país, principalmente em processos formais de aprendizagem de Espanhol por brasileiros.

Tal relação se pauta principalmente pelo imaginário de que a Língua Espanhola é fácil de ser aprendida, cujo processo de aprendizagem seria desnecessário como é salientado por Celada (2000), ao afirmar que o Espanhol para o brasileiro seria o desfrute de um gozo como falante de uma língua estrangeira, sem a necessidade de se submeter a um processo de aprendizagem, tendo como possibilidade de realização desta atitude o Portunhol. Em outros termos, a força desse imaginário se concretiza, sobretudo para o brasileiro, na realização de uma interlíngua que funciona como "saber" uma língua estrangeira: o Portunhol.

Quanto aos aspectos formais, a semelhança e a proximidade entre o Português e o Espanhol se tornam notáveis entre os falantes das duas línguas que se colocam em posição de

\footnotetext{
${ }^{5}$ As 10 macroestratégias foram publicadas em The postmethod condition: (E)merging strategies for second/foreign language teaching, pela TESOL Quarterly, volume 28, n. 1, em 1994, p. 32: “(a) maximize learning opportunities, (b) facilitate negotiated interaction, (c) minimize perceptual mismatches, (d) activate intuitive heuristics, (e) foster language awareness, (f) contextualize linguistic input, (g) integrate language skills, (h) promote learner autonomy, (i) raise cultural consciousness, and (j) ensure social relevance". Optamos pela publicação de Leffa (2012), com acréscimos na abordagem, por entendermos estar mais adaptada ao nosso contexto para esse relato.
} 
aprendente da outra, sobremaneira quando submetidos a abordagens que se apoiam, maiormente, em comparações de quadros lexicais e morfológicos nos quais o espaço da diferença estaria baseada nesses últimos. Entretanto, segundo Fanjul e González (2014),

[...] basta sair dos quadros, tabelas e armazéns de estoque e observar essas formas 'em ação' na fala e na escrita para ver que sua ocorrência ou não ocorrência obedece a restrições diferentes em cada língua, que a referência que estabelecem apresenta e desloca os objetos de outro modo, levando para informações distantes das que se tenta transmitir e/ou para grandes desencontros argumentativos e de atitudes em relação ao interlocutor e àquilo do qual se fala ou se tenta falar. (FANJUL; GONZÁLEZ, 2014, p. 21).

Disso decorre, especialmente no âmbito dos estudos referentes ao ensino de Espanhol para brasileiros, a construção de um espaço de reflexão que investiu fortemente em análises comparativas ou contrastivas do funcionamento linguístico de ambas as línguas. Nesses estudos, o imaginário de que as duas línguas são próximas é colocado em relação tanto discursivamente quanto a pontos formais. Tais estudos avalizam o necessário espaço da diferença entre elas e ressaltam o aspecto de que, apesar de sua pretensa proximidade, são, ao mesmo tempo, particularmente diferentes, ou, parafraseando Celada (2000), ao tratar sobre a especificidade da Língua Espanhola em nosso país, línguas singularmente estrangeiras aos falantes de cada uma delas que se empreendem na aprendizagem da outra.

Ponderamos, desse modo, importante no que se refere ao ensino de Português do Brasil para Hispânicos, que tal singularidade é também atuante, ou seja, é fundamental considerar, nessas práticas de ensino, a construção de "la justa medida de una cercanía" entre essas duas línguas estrangeiras (KULIKOWSKI E GONZÁLEZ, 1999), tão relativizada pelo senso comum e cujo funcionamento linguístico, segundo González (1994), é característico de uma "inversa assimetria" entre elas, assimetria que provoca fortes mobilizações no imaginário do falante de uma delas, que se submete à aprendizagem da outra e que, no caso da aprendizagem do Espanhol para brasileiros, possui um funcionamento discursivo baseado no imaginário ${ }^{7}$ de uma língua fácil de ser aprendida - imaginário que, em nossas práticas, verificamos não ser atuante.

Se, para Revuz (2002, p. 221), “aprender uma língua é sempre, um pouco, tornar-se um outro", se há o desafio de construir o espaço da diferença entre o Português e o Espanhol para aquele que aprenderá esta última como língua estrangeira, submetido a um forte gesto de homogeneidade linguística na escola ao aprender o Espanhol como língua materna, nomeadamente a grande variedade linguística dessa língua e sua relação com as demais línguas em situação minoritária ou de co-oficialidade, entendemos que, para o hispanofalante específico o do nosso perfil neste relato, que está na condição de aprendente de uma Língua Adicional e não estrangeira, o desafio ao aprender o Português do Brasil é o de assumir a heterogeneidade dessa língua, composta por diversas variedades com seus usos sociais e coletivos inerentes a essas variedades.

Nesse sentido, historicamente, podemos constatar que línguas e dialetos falados pelos índios nativos e pelos escravos africanos exerceram forte influência na língua que se consolidava em território brasileiro, sobretudo em aspectos lexicais, tanto no decorrer dos séculos de colonização, ainda que tenha havido proibição pelo Marquês de Pombal em 1758 para utilização de qualquer outra língua que não fosse a oficial portuguesa, quanto do final do século XIX e o século XX X $^{8}$ É a partir das contribuições de Mattoso Câmara Jr., reverberadas a

\footnotetext{
${ }^{6}$ A medida justa de uma proximidade [tradução nossa].

${ }^{7}$ Materializado, como dissemos, no Portunhol.

${ }^{8}$ Não é nosso objetivo, neste artigo, aprofundar questões sobre constituição do Português no Brasil, por isso apenas ilustramos alguns aspectos com vistas a atender ao entendimento de nosso relato.
} 
partir do quarto quartel do século $\mathrm{XX}$, que ocorre uma visão distinta, com base na ciência linguística, sobre a língua utilizada no Brasil, circunscrevendo-se a questão em três aspectos, basicamente, quanto à representação da língua: entre a língua do Brasil e a de Portugal, entre as modalidades falada e escrita e entre as variedades sociais culta e popular. Nesse caminho, no atual século, várias pesquisas abordam o Português caracteristicamente brasileiro, como exemplifica Farias (2014):

A primeira gramática de fôlego teórico e metodológico produzida por um(a) linguista é a Gramática de usos do português, de M. H. de Moura Neves (NEVES, 2000), que terá grande aceitação no meio acadêmico enquanto proposta de descrição do português em novas bases e será referência isolada, no seu gênero, para o estudo universitário do português por quase uma década. Após a gramática de Neves, mais para o final da década de 2000, intensificase a produção de gramáticas por linguistas brasileiros, sendo registradas, em ordem cronológica, as seguintes publicações:

Gramática Houaiss da língua portuguesa (AZEREDO, 2008),

Gramática do brasileiro (FERRAREZI JR.; TELES, 2008),

Gramática do português brasileiro (PERINI, 2010),

Nova gramática do português brasileiro (CASTILHO, 2010),

Gramática pedagógica do português brasileiro (BAGNO, 2011),

Pequena gramática do português brasileiro (CASTILHO; ELIAS, 2012)

e Gramática de bolso do português brasileiro (BAGNO, 2013).

(FARIAS, 2014, p. 109)

Desse modo, é possível afirmarmos, com base nas mais diversas pesquisas e descrições ${ }^{9}$, como as das gramáticas citadas acima, que há muitas diferenças para além do acervo lexical, envolvendo estruturas morfossintáticas, usos fonéticos, semânticos, pragmáticos. Alguns exemplos ilustram essas diferenças, como amplo uso de objeto nulo, prevalecimento das orações relativas "cortadoras" e "copiadoras", a queda do / $\mathrm{r}$ / final, principalmente nos verbos, a monotongação de [aj] antes de [J], aféreses, epêntese de [i] antes de /s/ final, palatalização de /s/ e /z/ finais de sílaba, monotongação de [ej] para [e], concordância no sintagma nominal, africação de /t/ e /d/ diante de /i/, quebra de encontros consonantais, dupla negação, entoação descendente, abertura das vogais pré-tônicas, pronúncia retroflexa do $/ \mathrm{r} /$, pronúncia do fonema $/ \lambda /$, uso ou omissão dos artigos definidos antes de nomes próprios e dos nomes de parentesco, uso de tu e você como pronomes de segunda pessoa, tendência a omitir o pronome reflexivo com verbos pronominais, nasalização heterossilábica, ausência de oposição entre $/ a / \mathrm{e} / \mathfrak{k} /$, manutenção das vogais pretônicas e postônicas $[\mathrm{e}],[\mathrm{o}] \mathrm{e}[\mathrm{u}]$, conservação do gerúndio, conservação da próclise em sentenças afirmativas com sujeito substantival anteposto, entre outros (ILARI E BASSO, 2006; MATTOSO CÂMARA JR., 1976; NARO E SCHERRE, 2007; TEYSSIER, 1997).

Analogamente, no espaço hispânico americano, identificamos variedade nos usos da Língua Espanhola em cada país, sendo mais evidenciada no léxico. No entanto, há uma diferença capaz de estabelecer maior unidade entre os vários países, defendida por Moreno Fernández (2000), para quem o Espanhol possui uma homogeneidade relativa, com variedades internas de diferentes áreas e de diferentes populações. Nesse ponto, cabe ressaltarmos que, mesmo com peculiaridades em determinados países e regiões, na visão de Moreno Fernández (2000), utiliza-se o mesmo idioma:

\footnotetext{
${ }^{9}$ A título de citação desses pesquisadores e teóricos: Mattos e Silva (2004, 2006), Lobo (1994, 1996, 2003, 2006), Naro (1981), Scherre (1988), Naro e Scherre (1993, 2003, 2007), Lucchesi (1999, 2003), Baxter e Lucchesi (1997, 2006).
} 
Volume 15 - Número 1 - jan/jul de 2020

La homogeneidade relativa de la lengua española está fundamentada en un sistema vocálico simple (5 elementos), un sistema consonántico con 17 unidades comunes a todos los hispanohablantes, en un importante léxico general, en lo que se refiere a los elementos léxicos estructurados, y una sintaxis que presenta una variación moderada, sobre todo en sus usos cultos ${ }^{10}$. (MORENO FERNÁNDEZ, 2000, p. 15)

No espaço boliviano, especificamente, embora haja quase 40 línguas oficiais de origem indígena, previstas na Constituição do país, o Censo de 2001 apresenta uma configuração de 1 terço bilíngue (Espanhol mais uma língua indígena), cerca de 11\% monolíngue de alguma língua indígena e quase $50 \%$ de monolíngues da língua espanhola, conformando uma diversidade bastante acentuada. Entre as línguas mais usadas, além do Espanhol, há o Quechua, o Aimara e o Chipaya, demarcando espaços linguístico-culturais em distintas regiões da Bolívia e definindo, também, espaços de maior prestígio social.

Ademais, na variedade da língua espanhola usada na Bolívia, existem contatos com as línguas indígenas que circunscrevem influências e possibilitam mudanças linguísticas, como atestam Aguilar, Huet e Pérez (2014), Mendoza (2012), Rivanedeira (2014b) e Rosa (2012), principalmente em La Paz, como uso particular de posposições (Dámelo nomás pues pero), dupla negativa (Nunca no me ha escuchado), alteração da ordem da frase, uso de duplo possessivo e uso da preposição en mais locativo (De mi mamá en su tienda estoy yendo), uso da preposição de ao invés de por (Ha llovido, de eso se ha mojado), uso do verbo saber com sentido de hábito (Sabe jugar fútbol los domingos), por exemplo.

Nesse ponto, cabe a nós explicitarmos que a problemática se instala mais fortemente quando se trata de uma Língua Adicional, como é o caso dos nossos aprendentes, especialmente, os bolivianos, que convivem em suas comunidades, na maioria, compostas por compatriotas de variadas regiões bolivianas e que, por isso, empregam sua(s) língua(s) de origem, não exatamente ou apenas a espanhola; em simultaneidade, estão em contato com brasileiros e precisam se comunicar. Isso gera, de um lado, sua necessidade de aprender o Português do Brasil, com sua diversidade ainda mais acentuada em São Paulo; por outro, há um nó nesse percurso, visto que compartilha a utilização do Espanhol da Bolívia em diversas situações de interação.

Desses aspectos decorre a importância de reiterarmos que toda língua sempre apresentará variação, justamente por ser essa condição a de potencializar as mudanças e, por isso, ocorrer em conformidade com as necessidades sociolinguísticas e interacionais dos grupos sociais. Isso se concretiza, via fatores externos ligados às classes sociais, gênero, etnia, idade e estilo/graus de formalidade-informalidade, além do espaço geográfico; contudo, permanecer apenas no que é linguístico, a partir de fatores internos de sua estrutura ${ }^{11}$, não explica, per si, o funcionamento de variedades em uma língua, mas sim, o modo como a língua se insere na sociedade e dela lança mão para a consecução de seus objetivos sociocomunicativos.

No caso do Brasil, as pesquisas sociolinguísticas vêm se desenvolvendo já há várias décadas e têm apresentado um mosaico de configurações bastante consistente quanto a variedades linguísticas brasileiras, o que torna seu ensino bem mais complexo quando se trata de um aprendente estrangeiro residente no nosso país. Nesse ponto de vista, cumpre-nos um caminho de mostrar ao aprendente não só a existência de variedades, mas também explicar esse funcionamento em nossas interações, recorrendo a exemplificações cotidianas, a fim de que se

\footnotetext{
${ }^{10}$ A relativa homogeneidade da Língua Espanhola é baseada em um sistema de vogais simples (5 elementos), um sistema consonantal com 17 unidades comuns a todos os falantes de Espanhol, em um importante léxico geral, com relação aos elementos lexicais estruturados, e uma sintaxe que apresenta uma variação moderada, especialmente em seus usos cultos. [tradução nossa]

${ }^{11}$ Não trataremos, nesse momento, dos fatores internos de estrutura da língua na ambiência de variedades.
} 
garanta um mínimo desenvolvimento de habilidades sociolinguísticas, já que em seus contatos com brasileiros essas variedades circularão com muita frequência.

Nessa conformidade, como crava Faraco (2008, p. 31), "não existe língua para além ou acima do conjunto das suas variedades constitutivas, nem existe a língua de um lado e as variedades do outro, como muitas vezes se acredita no senso comum: empiricamente a língua é o próprio conjunto de variedades". É dessa condição que acreditamos ser o percurso necessário ao ensino de Português do Brasil para Hispânicos e com o qual temos trabalhado em nossa prática, apesar de admitirmos que aparentemente exista uma preocupação entre os aprendentes hispânicos quanto ao uso de formas linguísticas mais próximas a uma norma de prestígio, preocupação que marca sobremaneira a interlíngua desses aprendizes em nosso curso, quando solicitam aulas com conteúdo gramaticais relacionados à norma culta.

Para um hispanofalante, a nosso ver, que se identifique com uma língua atravessada pela norma culta, sua projeção como alvo de aprendizagem torna-se aquela mais próxima de uma norma padrão culta da Língua Portuguesa, distante das variedades presentes em diversas práticas de letramento em Português com as quais geralmente os nossos alunos entram em contato em sua imersão no Brasil. Nesse ponto de vista, cabe-nos explicitar a dimensão que as variedades brasileiras apresentam em seus variados contextos de uso, a fim de localizar nosso aprendente em relação à importância de desenvolver habilidades sociolinguísticas em conformidade com os usos cotidianos nos processos de interação.

Nesse sentido, é importante frisarmos que no léxico de uma língua é que conhecemos inicialmente o repositório do saber linguístico de uma dada comunidade, além de nele podermos constatar como se configura a realidade extralinguística em determinada cultura, bem como do mundo que abriga esse léxico. Nesse ponto, ratificamos que o aprendente hispânico, ao utilizar seu léxico, poderá, sim, efetivar aprendizagens via interlíngua, todavia precisará entender com clareza a cultura brasileira, a fim de compreender a realidade sociocultural e acionar os usos que poderão garantir sua interação. Dessa maneira, acentuamos, ao trazermos Silva (2000, p. 142), que

o léxico constitui-se do saber vocabular de um grupo sociolinguístico e culturalmente definido; é o conhecimento partilhado que povoa a consciência do falante, onde esse acervo se configura como verdadeira janela através da qual o indivíduo divisa o seu entorno, ao mesmo tempo em que, ademais, revela os valores, as crenças, os costumes, os modismos que viabilizam a comunidade em que vive o usuário de tal e qual palavra. (SILVA, 2000, p. 142)

Acerca do ensino de línguas, na atualidade, Leffa (2012, p. 402) caracteriza três grandes linhas de ação:

A primeira é a substituição da abordagem comunicativa, como proposta unificada de ensino, por uma série de estratégias diversificadas que buscam atender as condições de aprendizagem do aluno, a realidade do professor e o contexto em que tudo isso ocorre, variando sempre de um lugar para outro. A segunda linha de ação diz respeito à integração da aprendizagem das línguas com o seu entorno, levando em consideração a realidade social do aluno; com a proposta prática de que a melhor maneira de integrar o aluno ao seu meio, desenvolvendo a cidadania, é pela implantação da pedagogia de projetos. Finalmente, a pedagogia dialógica permite ao professor construir com o aluno o conhecimento linguístico que historicamente valoriza o próprio contexto em que vivem. (LEFFA, 2012, p. 402) 
No que concerne à Metodologia por Tarefas, é fundamental a compreensão de que as tarefas têm objetivos comunicativos e são elaboradas a partir de atividades, gêneros e/ou prégêneros textuais orais e escritos de forma sequenciada (SWALLES, 1990). Para Long (2011), há princípios e características metodológicas do ensino baseado em tarefas que devem ser ressaltados, como o uso de tarefas e não de textos para nortear a didática, a promoção da aprendizagem por meio da prática e o foco no contexto, dentre outros. Ainda, é primordial salientarmos o que Norris (2001) legitima em relação ao fato de que as tarefas constituem planos teórico-pedagógicos e empíricos com vistas a alcançar, efetivamente, objetivos reais. Dessa forma, como observa Santos (2018, p. 1002), as pesquisas vêm confirmando que os aprendentes, durante a realização de tarefas orais em relação às lacunas e às diferenças entre a língua materna, a língua-alvo e seu sistema de interlíngua, estabelecem "novas relações entre forma/significado, que resultam na modificação do output e no desenvolvimento da língua".

Assim, postos tais aspectos e localizados os vieses teórico-conceituais, neste artigo, propomo-nos ao relato, na próxima seção, do trabalho cuja metodologia se ampara na utilização da interlíngua em turma de Português do Brasil para Hispânicos com base na metodologia de tarefas sobre as trocas acionadas na interação visando ao desenvolvimento da Língua Adicional.

\section{0 trabalho com a interlíngua: um relato de experiência}

Primeiramente, em nosso relato, destacamos que a sala de aula é um espaço imprescindível como lugar da prática social, para que a interação aluno-professor-colegas aconteça e frutifique em termos de desenvolvimento, permitindo e acionando a integração de habilidades sociolinguísticas e interação, bem como possibilitando a promoção da autonomia do aprendente.

Desse modo, em relação a trocas lexicais, salientamos, inicialmente, que, nas atividades de produção oral, com apresentação, diálogos, debates, por exemplo, utilizando-se de temáticas, eram recorrentes tais trocas entre o Português do Brasil e a Língua Espanhola pelos alunos quando eles se referiam a temas diretamente relacionados à sua vivência (trabalho, família, rotina) ou a temas diretamente relacionados à subjetividade (sentimentos, gostos, opiniões), assim como era comum nas interações orais o uso de vocabulário em Espanhol referente à família (madre, hijo, padre), a horários e ações do cotidiano (despertarse, acostarse, cenar), a gostos (me gusta, me encanta).

Nesse processo, retomando Kumaravadivelu (1994), observamos que as macroestratégias, na ampliação proposta por Leffa (2012, p. 399), visam a "facilitar ao aluno interação negociada com o professor e com os colegas para acelerar a compreensão e construção de sentido, usando, por exemplo, atividades em grupo" e a "ativar a heurística intuitiva dos alunos, fornecendo input linguístico suficiente para que eles possam chegar às regras da língua pela autodescoberta" e que se configuram como as mais adequadas quando os aprendentes recorrem diretamente a estruturas da língua de origem para preencher os espaços sociocognitivos e discursivos, uma vez que é necessário redimensionar o percurso para que eles compreendam a importância de elaborar o processamento em Português do Brasil, apelando ao Espanhol como interlíngua e não para ocupar tais espaços.

Nesse seguimento, nas primeiras aulas do curso, quando solicitamos a eles que descrevessem sua rotina durante a semana, utilizando-se de verbos no presente do indicativo e de horários para essa descrição, temas trabalhados durante as primeiras aulas e que, estruturalmente, não se distanciam do Espanhol. Assim, ao descrever ações realizadas em seu cotidiano, como as de acordar, almoçar, dormir e jantar, a retomada com os verbos em espanhol despertarse (Me despierto em vez de "Acordo"), comer (em vez de almoçar: Como a las doce no lugar de "Almoço ao meio-dia"), acostarse (Me acuesto no lugar de "Durmo") e cenar (Ceno a las ocho no lugar de "Janto às oito") foi recorrente, o que ratifica o estágio inicial de aquisição 
dos aprendentes e o imperativo que se apresentava para executar a macroestratégia "maximizar as oportunidades de aprendizagem, tratando a sala de aula como uma prática social conjunta entre professor e alunos" (LEFFA, 2012, p. 399; KUMARAVADIVELU, 1994, p. 32).

Também, a realização de trocas se notava quando abordamos temas diretamente relacionados à subjetividade, como os relacionados a sentimentos, gostos e opiniões. Para citarmos um exemplo, referente à expressão de gostos e sentimentos, em comparação com o Português, a sintaxe dos verbos relacionados a tais temas é diferente em Espanhol. Nesta língua, a pessoa que possui o gosto está marcada sintaticamente em uma posição de objeto indireto e o objeto que proporciona o gosto ou o sentimento está em posição de objeto direto. Tal sintaxe se constituía em uma dificuldade para que o aluno hispanofalante adotasse a sintaxe desses tipos de verbo em Português, cujo funcionamento é diferente. Nesse sentido, ao invés de ocorrências como "Meu filho gosta de ver televisão" ou "Minha mulher gosta de dormir cedo", eram realizadas ocorrências como "A mi hijo le gusta ver la televisión - ou televisão", mesclando léxicos em Português e Espanhol, ou "A mi esposa le gusta dormir temprano".

À vista disso, estruturas diferentes entre as línguas provocaram que os aprendentes se valessem dessa cognição no momento de expressão de seu envolvimento emocional. Isso nos indicou a necessidade de acionar a macroestratégia "ativar a heurística intuitiva dos alunos, fornecendo input linguístico suficiente para que eles possam chegar às regras da língua pela autodescoberta" (LEFFA, 2012, p. 400; KUMARAVADIVELU, 1994, p. 32), a fim de que os aprendentes pudessem se valer de elementos comuns do ponto sociointeracional e de entendimento sobre as estruturas distintas, com o propósito de que eles chegassem, buscando a interlíngua, a esse processamento.

Um segundo ponto de nosso relato refere-se "à integração da aprendizagem das línguas com o seu entorno, levando em consideração a realidade social do aluno" (LEFFA, 2012, p. 402). Nesse caso, nossa proposta partiu sempre de uma prática que melhor pudesse integrar o aluno às interações com brasileiros, desenvolvendo, em princípio, o aspecto sociolinguístico. Isso é corroborado na tarefa com uso de preposições, em que os aprendentes elaboram um mapa do percurso de sua residência até a escola, no qual deve ser descrito o caminho. Nessa tarefa, aparentemente para aprender a usar as preposições no Português do Brasil, o objetivo tem como princípio norteador que eles aprendam a explicar a um brasileiro como chegar a um local, ou seja, precisam elaborar seus conhecimentos sociolinguísticos e sociocomunicativos para o êxito da interação.

Para a consecução da atividade, eles apresentaram oralmente, com indicações no mapa elaborado, todo o trajeto realizado, com comentários sobre os lugares e como fazem o trajeto, se a pé, de bicicleta, de metrô ou de ônibus, por exemplo. Nesses momentos de explicação, acionamos as interações necessárias para haver uma compreensão que efetivasse $o$ entendimento de como se processam, do ponto de vista sociolinguístico e pragmático, formas de interagir com brasileiros, ou seja, tratamos de modos possíveis a serem mobilizados em situações concretas para utilização do Português do Brasil.

Sob o ângulo das preposições, em específico, relativo a distintas estruturas em cada língua, identificamos trocas mais recorrentes para os casos nos quais, de fato, do ponto de vista da estrutura linguística, as duas línguas apresentam uma significativa diferença. Por isso, as ocorrências de de la, en el, por la ratificaram nossa ideia de que os aprendentes precisariam mobilizar um conhecimento gramatical mais efetivo, a fim de que pudessem obter êxito no uso das preposições em Português. No entanto, verificamos que usos como hasta não tiveram ocorrência alta, o que nos indicia a possibilidade de compreensão dos processos de aprendizagem com o uso da interlíngua como mediadora, já que a transposição lexical pareceu ser suficiente no processo, mantendo-se a percepção de que as funções são iguais.

Nesse processo de aprendizagem, direcionamos as explicações para as diferenças das preposições entre as duas línguas e como elas se contraem ou não em Português, além de 
Volume 15 - Número 1 - jan/jul de 2020

mostrar as relações que elas estabelecem para os contextos linguísticos necessários para a compreensão de que perpassam seus usos em situações sociocomunicativas específicas, como quando indicam assunto, causa, destino, distância, finalidade, instrumento, origem e preço, bem como as relações estabelecidas com pronomes e, principalmente, com os advérbios de tempo e de lugar.

$\mathrm{Na}$ sequência desse relato, tratamos do que Leffa (2012) denomina "pedagogia dialógica", em que a construção do conhecimento e, por conseguinte, a aprendizagem efetiva acontecem sob um prisma historicamente valorizado a partir do(s) contexto(s) em que tal comunidade vive e das relações que ela mantém em seu entorno e para além desse entorno. $\mathrm{Na}$ tarefa, a partir de um roteiro que resgata informações desde quando ainda se encontravam em seu país de origem, eles produziram uma apresentação oral, com informações pessoais e profissionais (nome completo, idade, de que cidade e país é, profissão e do que mais gosta no Brasil), bem como a rotina da semana em São Paulo (o que faz, para onde vai, onde almoça etc), também colocaram em prática as aprendizagens desenvolvidas no decorrer do curso.

Com essa tarefa, em que eles puderam se retratar efetivamente e, de certo modo, apresentar uma visão pessoal de sua história como imigrante, constatamos mais concretamente que havia um dispositivo cognitivo acionado para recorrer ao Espanhol sempre que se tratava de algo mais íntimo ou subjetivo, de um lado; de outro, a falta de um acervo lexical em Português contribuiu para legitimar o uso da interlíngua. Em relação a estruturas propriamente que são muito diferentes nas duas línguas, construções com verbos no pretérito perfeito permaneceram presentes na fala deles, mas usos de artigos e de pronomes foram feitos em Português do Brasil, exceto quando utilizados em estruturas com preposições, sem recorrer a estruturas do Espanhol, inclusive com pronomes retos na posição de complemento verbal, caso bastante típico do Português do Brasil.

Com isso, buscamos delinear um itinerário de pensar em educação linguística como algo voltado a promover o letramento na direção de se colocar o ensino da Língua Adicional "a serviço de garantir as condições para que os educandos tenham elementos para perceber os limites que os seus recursos linguísticos podem impor à sua atuação e também as condições para que possam superar esses limites" (SCHLATTER; GARCEZ, 2009, p. 134-135), o que remete a nosso objetivo de tratar das relações sociolinguísticas e interacionais, visto que a proximidade das estruturas linguísticas nas duas línguas capitalizam os elementos necessários para ativar recursos substanciais no processo tanto de acionar saberes na Língua Espanhola quanto na Língua Portuguesa, por sua familiaridade, e simultaneamente reunir possibilidades de superar as diferenças, avivando a interlíngua.

\section{Considerações finais}

Neste artigo, relatamos a experiência de ensino de Português do Brasil para Hispânicos como Língua Adicional em uma perspectiva de aprendizagem via interlíngua como estratégia efetiva de aprendizagem, a partir da metodologia por tarefas. Sob essa orientação, podemos compreender o ensino de Português, enfocado nesse percurso metodológico, como uma maneira prática de constituição de interações multi e interlinguísticas em uma representação reflexiva da comunicação entre as diversas variedades brasileiras, explicando ao aprendente esse funcionamento dentro da nossa cultura, com exemplos práticas do nosso dia a dia, e possibilitando autonomia em seus contatos com brasileiros, bem como uso dessas variedades que circulam com muita frequência.

Por isso, nessa perspectiva, pontuamos como os aprendentes hispânicos mobilizam e articulam conhecimentos prévios de sua língua, acoplando-os ao Português do Brasil, à proporção que buscam interações cujos propósitos residem em situá-los sociolinguisticamente no espaço de uso brasileiro para fins comunicativos. Sob esse mote, abarcamos, em nosso relato, 
Volume 15 - Número 1 - jan/jul de 2020

competência gramatical, sociolinguística e pragmática, conforme desenvolvemos as tarefas, a fim de dimensionar empregos da/na língua como um caminho de domínio sociocomunicativo de modo a proporcionar o desenvolvimento de habilidades para lidar no cotidiano com as semelhanças e as diferenças entre o Português do Brasil e a língua espanhola, ressaltando a importância da interlíngua e entendendo o Português do Brasil como Língua Adicional.

Assim, ao pensarmos uma vivência de cenários concretos para o crescimento vertical e horizontal do conhecimento da língua, aplicado a práticas cotidianas, entendemos que sua inserção no contexto sociolinguístico possa acontecer de maneira mais real, sem que seus laços linguístico-culturais com a Bolívia se percam ou sejam preteridas, visto que muitos da comunidade boliviana não pretendem permanecer no Brasil, isto é, estão para trabalhar e não para se tornar um cidadão brasileiro (pelo menos, por inferência, a partir de conversas em aula, é o que observamos). Nessa suposição de expectativas, o ensino da língua utilizada no Brasil acaba ganhando contornos diversos em se tratando dos objetivos individualmente postos, sendo necessário articular da melhor forma todos esses lugares simbólicos, o que nos parece acontecer considerada a adoção do ensino de Português do Brasil como Língua Adicional.

\section{Referências}

AGUILAR, M. J.; HUET, M.; PÉREZ, S. Diccionario ejemplificado e ilustrado de bolivianismos, DEIB. In XVII Congreso Internacional Asociacion de Linguistica y Filologia de America Latina (ALFAL), João Pessoa, p. 2209-2219, 2014.

CELADA, M. T. O espanhol para o brasileiro. Uma língua singularmente estrangeira. Tese (Doutorado), Unicamp, IEL, 2000. Disponível em: http://www.fflch.usp.br/dlm/espanhol/docente/Tese_MaiteCelada.pdf. Acesso: 05 abr.2020

DELMANTO, D.; FAUSTINONI, E. Os relatos de prática e sua importância no processo de produção e socialização do conhecimento. In GOIÁS. Secretaria de Estado da Educação. Reorientação curricular do $6^{\circ}$ ao $9^{\circ}$ ano: currículo em debate - relatos de práticas pedagógicas. Goiânia, 2009.

FANJUL, A.; GONZÁLEZ, N. T. M. Políticas do saber e (re)descoberta das línguas. In FANJUL, A.; GONZÁleZ, N. T. M. (orgs.) Espanhol e Português Brasileiro: estudos comparados. São Paulo: Parábola Editora, 2014. p. 29-50.

FARACO, C. A. Norma culta brasileira: desatando alguns nós. São Paulo: Parábola Editorial, 2008.

FARIAS, W. S. de. As gramáticas dos linguistas no Brasil: efeitos de sentido polêmicos sobre a língua a re-conhecer. Linguagem em (Dis)curso - LemD, Tubarão, SC, v. 14, n. 1, p. 105 122, jan./abr. 2014.

GONZALEZ, N. T. M. Cadê o pronome? O gato comeu. Os pronomes pessoais na aquisição /aprendizagem do espanhol por brasileiros adultos. Tese (Doutorado em Linguística). Faculdade de Filosofia, Letras e Ciências Humanas, Universidade de São Paulo, São Paulo, 1994.

ILARI, R.; BASSO, R. O português da gente: a língua que estudamos, a língua que falamos. São Paulo: Contexto, 2006.

KULIKOWSKI, M. Z. M.; GONZÁLEZ, N. T. M. Español para brasileños. Sobre por donde determinar la justa medida de una cercanía. Anuario brasileño de estudios hispánicos, n. 9, p. 11-19.

KUMARAVADIVELU, B. The postmethod condition: (E)merging strategies for second/foreign language teaching. TESOL Quarterly, v. 28, n. 1, p. 27-48, 1994.

LEFFA, V. Ensino de línguas: passado, presente e futuro. Rev. Est. Ling., Belo Horizonte, v. 20, n. 2, p. 389-411, jul./dez. 2012. 
Volume 15 - Número 1 - jan/jul de 2020

LONG, M. H. Methodological principles for language teaching. In LONG, M. H.; DOUGHTY, C. J. The handbook of language teaching. Oxford: Wiley-Blackwell, 2011. p. 373-397.

MATTOSO CÂMARA JR., J. História e estrutura da língua portuguesa. 2. ed. Rio de Janeiro: Padrão, 1976.

MENDOZA, J. Antecedentes linguísticos para una fisonomía del castellano de Bolivia. Discurso de ingreso a la ABL, Centro Cultural de España, 2012.

MOLINA, J. L. G. L'apprenant, notion émergente. Education Permanent, n. 147, p. 77-85, 2001.

MORENO FERNÁNDEZ, F. ¿Qué español enseñar? Madrid: Arcolibros, 2000.

NARO, A. J.; SCHERRE, M. M. P. Origens do português brasileiro. São Paulo: Parábola Editoral, 2007.

NORRIS, J. M. Identiying rating criteria for task-based EAP assesment. In HUDSON, T. D.; BROWN, J. D. (eds.). A focus on language test development: expanding the language proficiency construct across a variety os tests. Honolulu, III: University of Hawai Press, 2001. PEREIRA, A. M. de S. L. do V. Alunos, aprendentes e aprendizes: um estudo etnobiográfico sobre percursos de formação. Dissertação (Doutorado). Faculdade de Psicologia e Ciências da Educação, Universidade do Porto, 2003. 826p.

REVUZ, C. A língua estrangeira entre o desejo de outro lugar e o risco do exílio. In SIGNORINI, I. (org.) Língua(gem) e identidade. Campinas: Mercado de Letras, 2002.

RIVADENEIRA, R. Bolivianismos en el dicionário de la lengua espanola. 23. ed. La Paz Bolívia: Plural, 2014.

ROSA, J. M. Diatelogia do español. Natal, Brasil: IFRN Editora, 2012.

TEYSSIER, P. História da língua portuguesa. São Paulo: Martins Fontes, 1997.

ROTTAVA, L.; SILVA, A. M. da. Influência interlinguística no processo de escrita em Português LE-Adicional. In SILVA, K. A. da; SANTOS, D. T. dos. Português como língua (inter)nacional: faces e interfaces. Campinas/SP: Pontes Editores, 2013. p. 275-297.

SANTOS, S. A competência oral: uma abordagem por tarefas. Domínios de Lingu@gem. Uberlândia, vol. 12, n. 2, p. 1000-1020, abr-jun.2018.

SCHLATTER, M; GARCEZ, P. M. Línguas Adicionais (Espanhol e Inglês). Rio Grande do Sul, Secretaria de Estado da Educação, Departamento Pedagógico. (Orgs.). Referências Curriculares do Estado do Rio Grande do Sul: linguagem, códigos e suas tecnologias. Porto Alegre: Secretaria de Estado da Educação, Departamento Pedagógico, 2009, v. 1, p. 127-172.

SCHOFFEN, J. R. Gêneros do discurso e parâmetros de avaliação de proficiência em português como língua estrangeira no exame Celpe-Bras. Tese (Doutorado). UFRGS, Porto Alegre, 2009.

SCHÖN, D. Educando o profissional reflexivo: um novo design para o ensino e a aprendizagem. Porto Alegre: Artmed, 2000.

SILVA, M. E. B. da. O dinamismo lexical: o dizer nosso de cada dia. In AZEREDO, J. C. de (Org.). A língua portuguesa em debate: conhecimento e ensino. Petrópolis: Vozes, 2000.

SWALES, J. M. Genre Analysis: english in academic and research settings. $13^{\mathrm{a}}$ ed. Cambridge: Cambridge University Press, 1990. 1-82 p.

VOISIN, A. L'apprenant introuvable ou les incertitudes de la recherche. Education Permanent, n. 147-2, p. 63-75, 2001.

Submetido em 30/04/20

Aceito em 13/08/20 